Methods: 50 consecutive Spanish patients undergoing periodic treatment with TCZ who fulfilled the 2010 classification criteria for RA [5] were recruited. Adiponectin serum levels were assessed in samples obtained immediately prior to (pre-infusion) and 60 minutes after the end of a TCZ intravenous infusion (post-infusion) by a commercial Enzyme-Linked ImmunoSorbent Assay (ELISA) kit. Results: Similar serum levels of adiponectin were found following the TCZ infusion (mean \pm standard deviation: $23.01 \pm 18.58 \mu \mathrm{g} / \mathrm{mL}$ versus $22.35 \pm 17.84$ $\mu \mathrm{g} / \mathrm{mL}$, pre- and post-infusion, respectively, $\mathrm{p}=0.69$ ). Additionally, there was a negative correlation between adiponectin basal levels and body mass index ( $r=-$ $0.45, p<0.01)$, insulin $(r=-0.33, p=0.02)$, insulin/glucose index $(r=-0.32, p=0.03)$ and C-peptide levels $(r=-0.32, p=0.03)$ of RA patients, whereas a strong positive correlation was observed with HDL-cholesterol levels $(r=0.51, p<0.01)$. Moreover, basal levels of adiponectin were significantly lower in obese patients when compared to those with normal weight $(p=0.03)$

Conclusion: Our study suggests that anti-IL-6 therapy has no short-term effect on adiponectin serum levels in patients with RA. Furthermore, our results support that low adiponectin levels are associated with MetS features and, therefore, with CV disease in RA.

REFERENCES:

[1] Biochem Pharmacol. 2019;165:196-206; [2] Clin Exp Rheumatol. 2008;26:596-603; [3] Mediators Inflamm. 2013;2013:710928; [4] Clin Exp Rheumatol 2020;38:1201-1205; [5] Arthritis Rheum. 2010;62:2569-2581. Acknowledgements: Personal funds: SR-M: RD16/0012/0009 (ISCIII-ERDF);VP-C: PREVAL 18/01 (IDIVAL); OG: GPC IN607B2019/10 (GAIN); RL-M: Miguel Servet type I programme CP16/00033 (ISCIII-ESF).

Disclosure of Interests: Sara Remuzgo-Martínez: None declared, Verónica Pulito-Cueto: None declared, Fernanda Genre: None declared, Jaime Calvo: None declared, Elena Aurrecoechea: None declared, Irene Llorente: None declared, Ana Triguero-Martinez: None declared, Ricardo Blanco Speakers bureau: Abbvie, Pfizer, Roche, Bristol-Myers, Janssen and MSD, Consultant of: Abbvie, Pfizer, Roche, Bristol-Myers, Janssen and MSD, Grant/research support from: Abbvie, MSD and Roche, Javier Llorca: None declared, M E Ruiz: None declared, Natalia Rivera: None declared, Oreste Gualillo: None declared, Raquel López-Mejías: None declared, Santos Castañeda: None declared, Miguel A González-Gay Speakers bureau: Pfizer, Abbvie, MSD, Grant/research support from: Pfizer, Abbvie, MSD. DOI: 10.1136/annrheumdis-2021-eular.2739

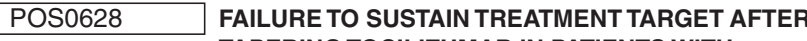 TAPERING TOCILIZUMAB IN PATIENTS WITH RHEUMATOID ARTHRITIS: 4-YEAR LONGITUDINAL DATA FROM A NATIONWIDE COHORT}

J.W. Park ${ }^{1}$, M. J. Kim², H. A. Kim ${ }^{3}$, J. Kim", E. B. Lee', K. Shin' ${ }^{1}{ }^{1}$ Seoul National University College of Medicine, Division of Rheumatology, Department of Internal Medicine, Seoul, Korea, Rep. of (South Korea); ${ }^{2}$ Seoul Metropolitan Government - Seoul Boramae Medical Center, Division of Rheumatology, Department of Internal Medicine, Seoul, Korea, Rep. of (South Korea); ${ }^{3}$ Ajou University School of Medicine, Department of Rheumatology, Suwon, Korea, Rep. of (South Korea); ${ }^{4}$ Chungnam National University College of Medicine, Division of Rheumatology, Department of Internal Medicine, Daejeon, Korea, Rep. of (South Korea)

Background: Tapering biologic therapy after achieving clinical remission or low disease activity (LDA) has become a viable option in daily clinical practice of treating patients with rheumatoid arthritis (RA). There are yet few studies investigating its effectiveness and safety compared with those of standard biologic treatment, especially with non-tumor necrosis factor inhibitors.

Objectives: To investigate the effectiveness and safety of tapering tocilizumab (TCZ) in patients with RA who attained LDA after TCZ therapy.

Methods: Data were collected from a nationwide cohort of patients with RA receiving biologic therapy in South Korea (KOBIO-RA). This study included 350 patients who were treated with TCZ and achieved Clinical Disease Activity Index (CDAI)-LDA or remission $(C D A I \leq 10)$ after one year of treatment. We performed a longitudinal analysis utilizing clinical data measured in all 1-year intervals using generalized estimating equations (GEE). A total of 575 one-year intervals were divided into two groups according to the dose quotient (DQ, $0-100 \%$ ) of TCZ within the interval (tapering group vs. standard treatment group). The main outcome of this study was loss of CDAI-LDA in the following 1-year interval.

Results: Tapering TCZ was conducted in $282(49.0 \%)$ intervals with a mean (SD) DQ of 66.0 (15.5). Loss of CDAI-LDA occurred in 91 (15.1\%) intervals. Multivariable GEE showed significantly increased loss of CDAI-LDA (adjusted OR $(95 \% \mathrm{Cl}): 1.76$ [1.01 to 3.07$])$ in the tapering group after adjusting for previous biologics use, route of TCZ administration, concomitant glucocorticoid use, and CDAI measured in the previous follow-up. In addition, the likelihood to achieve DAS28-deep remission (DAS28-ESR $<1.98$ ) was also significantly lower in the tapering group (adjusted OR 0.68 [0.46 to 0.99]). In contrast, there was no significant difference in the proportion of fulfilling other remission criteria between the two groups (Table 1). Development any adverse drug event or event of special interest was comparable in both groups except for hypercholesterolemia, which was lower in the tapering group.

Table 1. The effect of tapering tocilizumab on achieving outcomes

\begin{tabular}{|c|c|c|c|c|c|c|}
\hline & $\begin{array}{l}\text { Loss of } \\
\text { CDAI-LDA }\end{array}$ & $\begin{array}{l}\text { DAS28- } \\
\text { remission }\end{array}$ & $\begin{array}{l}\text { DAS28-deep } \\
\text { remission }\end{array}$ & $\begin{array}{l}\text { CDAI- } \\
\text { remission }\end{array}$ & $\begin{array}{l}\text { SDAl- } \\
\text { remission }\end{array}$ & $\begin{array}{c}\text { ACR/ } \\
\text { EULAR } \\
\text { remission }\end{array}$ \\
\hline $\begin{array}{l}\text { Unadjusted OR } \\
\qquad \begin{array}{l}(95 \% \mathrm{CI}) \text { (vs. } \\
\text { standard-dose } \\
\text { group) }\end{array}\end{array}$ & $\begin{array}{c}1.02(0.67 \\
\text { to } 1.55)\end{array}$ & $\begin{array}{c}1.03(0.71 \\
\text { to } 1.49)\end{array}$ & $\begin{array}{c}0.76(0.54 \mathrm{t} \\
01.06)\end{array}$ & $\begin{array}{c}1.23(0.75 \\
\text { to } 2.00)\end{array}$ & $\begin{array}{c}0.92(0.59 \\
\text { to } 1.44)\end{array}$ & $\begin{array}{c}0.98(0.65 \text { to } \\
1.48)\end{array}$ \\
\hline $\begin{array}{l}\text { Adjusted OR } \\
(95 \% \mathrm{Cl}) \text { (vs. } \\
\text { standard-dose } \\
\text { group) }\end{array}$ & $\begin{array}{c}1.76(1.01 \\
\text { to } 3.07)\end{array}$ & $\begin{array}{c}0.87(0.54 \\
\text { to } 1.38)\end{array}$ & $\begin{array}{c}0.68 \text { (0.46 to } \\
0.99)\end{array}$ & $\begin{array}{c}0.94(0.57 \\
\text { to } 1.55)\end{array}$ & $\begin{array}{c}0.87(0.54 \\
\text { to } 1.38)\end{array}$ & $\begin{array}{c}0.76(0.50 \\
\text { to } 1.18)\end{array}$ \\
\hline
\end{tabular}

CDAl, clinical disease activity index; $\mathrm{Cl}$, confidence interval; DAS, disease activity score; LDA, low disease activity; OR, odds ratio; SDAI, simplified disease activity index.

Conclusion: Tapering TCZ after achieving LDA in patients with RA increases the risk of losing the benefit of LDA without a significant merit in safety. REFERENCES:

[1] Smolen JS et al. Maintenance, reduction or withdrawal of etanercept after treatment with etanercept and methotrexate in patients with moderate rheumatoid arthritis (PRESERVE): a randomised controlled trial. Lancet 2013;381:918-29.

[2] Schett $\mathrm{G}$ et al. Tapering biologic and conventional DMARD therapy in rheumatoid arthritis: current evidence and future directions. Ann Rheum Dis. 2016;75:1428-37.

Disclosure of Interests: None declared

DOI: 10.1136/annrheumdis-2021-eular.2818

\section{POS0629 \\ PREDICTORS OF CHANGE IN DISEASE ACTIVITY IN RHEUMATOID ARTHRITIS AFTER START OF TREATMENT WITH ABATACEPT}

J. Liukkonen ${ }^{1}$, G. Cagnotto ${ }^{1,2}$, J. Å. Nilsson ${ }^{1,2}$, S. Saevarsdottir ${ }^{3,4}, \underline{\text { C. Turesson }}{ }^{1,2}$ ${ }^{1}$ Lund University, Rheumatology, Department of Clinical Sciences, Malmö, Malmö, Sweden; ${ }^{2}$ Skåne University Hospital, Department of Rheumatology, Malmö, Sweden; ${ }^{3}$ Karolinska Institutet, Division of Clinical Epidemiology, Department of Medicine, Stockholm, Sweden; ${ }^{4}$ University of Iceland, Faculty of Medicine, School of Health Sciences, Reykjavik, Iceland

Background: Abatacept is a biologic disease-modifying anti-rheumatic drug (bDMARD) used to treat rheumatoid arthritis (RA) since 2006, acting by inhibition of T-cell co-stimulation. There are limited data on factors predicting clinical outcomes in RA after start of treatment with abatacept.

Objectives: The primary aim was to identify predictors of change in disease activity in RA-patients after start of treatment with abatacept.

Methods: This cohort study was based on data from the Swedish Rheumatology Quality register (SRQ). All patients with RA who started treatment with abatacept between 2006 and 2017 were included. Clinical data from the SRQ included demographics, disease characteristics and antirheumatic treatment Disease activity was measured according to DAS28-ESR (Disease Activity Score of 28 joints based on erythrocyte sedimentation rate) at inclusion and at follow-up visits at 6 and 12 months from start of treatment with abatacept. Baseline predictors of change in disease activity were investigated using linear regression models bivariately and adjusted for baseline values of DAS28. Covariates with a $p$-value of $<0.1$ were retained for the final multivariate model. In case of covariates with major collinearity, the one with the stronger association with change of DAS28 was selected.

Results: In a total of 2716 patients, 872 had data on change in DAS28 at 12 months. Among these, most patients were women $(79.6 \%)$ and the mean age at start of abatacept was 58.4 years (SD 13.6). The majority of patients had established RA, with a mean disease duration of 13.5 years (SD 11.1). Most patients had severe, active disease, with substantial pain and disability, despite extensive treatment. The mean number of bDMARDs that a patient had been exposed to was 1.90 (SD 1.32). DAS28 decreased significantly over the first year (mean 1.22

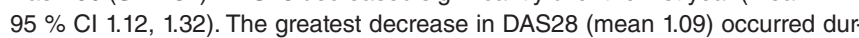
ing the first 6 months from start of abatacept. The multivariate regression mode identified male sex and limited previous bDMARD exposure as independent predictors of change in DAS28 at 12 months from start of abatacept - adjusted for baseline DAS28, RA duration and current treatment with methotrexate or prednisolone (Table 1).

Conclusion: In this national register study, male sex and limited previous exposure to bDMARDs were independent predictors of reduction of disease activity one year after start of treatment with abatacept for RA, possibly reflecting a better prognosis overall in such patients. 